\title{
Correction to: Sordaria fimicola-like ascomycete isolated from Pinus coulteri. Needles in Slovakia
}

\author{
Helena Ivanová ${ }^{1}$ Anna Onderková ${ }^{2}$ P Peter Pristaš ${ }^{2,3}$
}

Published online: 25 June 2018

(C) Plant Science and Biodiversity Centre, Slovak Academy of Sciences 2018

\section{Correction to: Polar Biol}

https://doi.org/10.2478/s11756-018-0071-0

The original version of this article has been corrected to reflect the proper rendering of Fig. 1 after it was reported by the author that Fig. 1 was not loaded properly and did not show all of the necessary information. The original article has been corrected.

The online version of the original article can be found at https://doi.org/ 10.2478/s11756-018-0071-0

Helena Ivanová

helena.ivanova@ife.sk

1 Department of Plant Pathology and Mycology, Institute of Forest Ecology of the Slovak Academy of Sciences, Akademická 2, 949 01 Nitra, Slovak Republic

2 Institute of Biology and Ecology, Pavol Jozef Šafárik University, Košice, Slovak Republic

3 Institute of Animal Physiology of the Slovak Academy of Sciences, Košice, Slovak Republic 